\title{
Study on the Properties of $\mathrm{Nano}-\mathrm{Al}_{2} \mathrm{O}_{3} /$ Phenyl Silicone Rubber Composites
}

\author{
Yan XUa , Qun GAO ${ }^{\text {b, }}$, Chun-Fa OUYANG ${ }^{c}$, Hong GUO ${ }^{d}$, Xu XIANG ${ }^{e}$ \\ School of Materials Science \& Engineering, Shanghai Institute of Technology, Shanghai, 201418, \\ China \\ axxyxshchj@163.com, ${ }^{b, *}$ wityy@sit.edu.cn, ouyoung_0916@163.com, 'guohong0506@126.com, \\ exijiyumingxi@163.com \\ ${ }^{*}$ Corresponding author
}

Keywords: Nano- $\mathrm{Al}_{2} \mathrm{O}_{3}$, Phenyl Silicone Rubber, Composites, Low Loading.

\begin{abstract}
Nanoparticles filled silicone rubber is widely used in electric encapsulation for its excellent insulating properties, thermal and optical stability. This paper focuses on the effect of nano- $\mathrm{Al}_{2} \mathrm{O}_{3}$ on the properties of phenyl silicone rubber at low loading $(\leq 1 \%)$. Nano- $\mathrm{Al}_{2} \mathrm{O}_{3}$ was modified by silane coupling agent (KH550) and added to phenyl silicone rubber by solution mixing method. The mixture was cured at room temperature to obtain nano- $\mathrm{Al}_{2} \mathrm{O}_{3} /$ phenyl silicone rubber composites. The structure of modified nano- $\mathrm{Al}_{2} \mathrm{O}_{3}$ and the resultant composites were characterized by FT-IR spectra, TGA, UV-vis spectroscopy, thermal conductivity meter and tensile testing. The results indicate that the composites showed high thermal conductivity of $0.216 \mathrm{~W} \cdot \mathrm{m}^{-1} \cdot \mathrm{K}^{-1}$, high tensile strength of $0.25 \mathrm{MPa}$ with the addition of $0.06 \mathrm{wt} \%$ nano- $\mathrm{Al}_{2} \mathrm{O}_{3}$. The transmittance of phenyl silicone rubber is gradually decline with the increase of filler loading. In the ultraviolet-visible region, the transmittance of composites is lower than that of pure phenyl silicone rubber. Nano- $\mathrm{Al}_{2} \mathrm{O}_{3}$ shows a high UV shielding ability comparing to pure silicone rubber. The thermal and mechanical properties of modified silicone rubber do not improve obviously at the low filler loading.
\end{abstract}

\section{Introduction}

Silicone rubber is stable in a wide range of temperatures and has lots of distinctive characteristics, such as excellent elasticity, oxidation resistance, aging resistance, low toxicity and electrical-insulating properties[1-4]. Phenyl silicone rubber is one of the specific silicone rubber, which is formed by introducing a certain proportion of methyl phenyl siloxane or diphenyl siloxane segments into the main chain of dimethyl silicone rubber. It is commonly used as electronic packaging materials. However, the pure phenyl silicone rubber shows poorer heat-conducting and dielectric properties, which limits its application as flexible dielectric materials. In order to broaden the application of phenyl silicone rubber, we require to modify silicone rubber with higher thermal conductivity and electrical insulation, which can be achieved by the use of suitable heat conductive and electric insulated fillers such as nano $\mathrm{AlN}, \mathrm{SiC}, \mathrm{Al} 2 \mathrm{O} 3[5]$, etc.

Alumina $\left(\mathrm{Al}_{2} \mathrm{O}_{3}\right)$ exists in a great variety of metastable transition phase commonly, including $\gamma-$, $\delta-, \theta-, \eta-, \chi-$, and $\kappa-\mathrm{Al}_{2} \mathrm{O}_{3}$, as well as stable $\alpha-\mathrm{Al}_{2} \mathrm{O}_{3}$ phase. Nano- $\mathrm{Al}_{2} \mathrm{O}_{3}$ as modified filler, not only has advantageous structure of uniform composition, fine particle size, narrow particle size distribution, no agglomeration, large surface area, but also has high conductive resistivity, high hardness, high melting point, excellent chemical stability[6-10].

The effects of content and particle size of nano- $\mathrm{Al}_{2} \mathrm{O}_{3}$ filler on the electrical conductivity, thermal conductivity and mechanical property of silicone rubber are already investigated[11-14]. However, reports with phenyl silicone rubber as the polymer matrix are relatively few. In this paper, $\gamma-\mathrm{Al}_{2} \mathrm{O}_{3}$ was chosen as filler and modified by silane coupling agent. The effect of low filler loading on the 
thermal conductivity, transmittance and mechanical properties of the composites were investigated by thermal conductivity meter, UV-vis spectroscopy and tensile testing.

\section{Experimental}

\section{Materials}

Nano- $\mathrm{Al}_{2} \mathrm{O}_{3}(\sim 20 \mathrm{~nm}), \gamma$-crysta, was provided by Beijing daoking nano technology, China.

Phenyl silicone rubber used in this study, is $\alpha, \omega$-dihydroxy poly dimethyl diphenyl siloxane (108-1), was purchased from Shanghai resin factory, China. The phenyl content was $9.3 \mathrm{wt} \%$.

Dibutyltin dilaurate (DBTDL) and tetraethyl orthosilicate (TEOS) used as catalyst and curing agent, were purchased from Sinopharm Chemical Reagent Co., Ltd, China.

Silane coupling agent(KH550), ethanol (AR) were purchased from Sinopharm Chemical Reagent Co., Ltd, China.

\section{Preparation of $\mathrm{KH} 550$ Modified $\mathrm{Nano}-\mathrm{Al}_{2} \mathrm{O}_{3}$}

The nano- $\mathrm{Al}_{2} \mathrm{O}_{3}$ was drying in the vacuum at $80^{\circ} \mathrm{C}$ for $3 \mathrm{~h}$ to exclude the impact of air and moisture. Amounts of nano- $\mathrm{Al}_{2} \mathrm{O}_{3}$ were sonicated in anhydrous ethanol for $20 \mathrm{~min}$ to form homogeneous dispersion. Moderate KH550 was added in the dispersion. The mixture was stirred and refluxed at $80^{\circ} \mathrm{C}$ for $3 \mathrm{~h}$. After cooling to room temperature, the resultant was centrifuged and washed repeatedly with anhydrous ethanol to remove the residual KH550. The solid product was dried in vacuum oven at $60^{\circ} \mathrm{C}$ overnight. After grinding, $\mathrm{KH} 550$ modified nano- $\mathrm{Al}_{2} \mathrm{O}_{3}$ (KH550/nano- $\mathrm{Al}_{2} \mathrm{O}_{3}$ ) was obtained.

\section{Preparation of Nano- $\mathrm{Al}_{2} \mathrm{O}_{3} /$ phenyl Silicone Rubber Composites}

The filler were dispersed in ethanol by ultrasonic for $20 \mathrm{~min}$. The dispersion was mixed with phenyl silicone rubber uniformly. The mixture was dried in vacuum oven at $80^{\circ} \mathrm{C}$. Then $5 \mathrm{wt} \%$ TEOS and $2 \mathrm{wt} \%$ DBTDL were added to the mixture with stir. The mixture was then poured into round polypropylene mold and vacuumed at room temperature for 30min to remove bubbles generated during the process of mixing. At last, the mixture was cured at $80^{\circ} \mathrm{C}$ for $2 \mathrm{~h}$ to obtain nano- $\mathrm{Al}_{2} \mathrm{O}_{3} /$ phenyl silicone rubber.

\section{Characterization}

Fourier transform infrared (FT-IR) spectra were recorded on a Nicolet 380 (USA) Fourier transform infrared spectrometer, with $\mathrm{KBr}$ pellets, scanning from $4000-400 \mathrm{~cm}^{-1}$ repeatedly for 8 times.

Weight loss of the nano- $\mathrm{Al}_{2} \mathrm{O}_{3}$ was characterized by thermogravimetric analysis (TGA) using a TGA-7 thermogravimetric analyzer (PerkinElmer, USA) under air atmosphere from 40 to $800^{\circ} \mathrm{C}$ at a heating rate of $10^{\circ} \mathrm{C} / \mathrm{min}$.

The transmittance of nanocomposites was measured by $754 \mathrm{~N}$ ultraviolet visible (UV-Vis) spectrophotometer (Shanghai APL instrument, China), on the base of air, in the range of $200-1000 \mathrm{~nm}$ at a resolution of $1 \mathrm{~nm}$.

Thermal conductivity was investigated under steady state condition, utilizing LFA447 laser thermal conductivity meter (NETZSCH instruments North America, LLC, Germany) according to ASTM E-1461. This thermal analyzer was chosen over the flash method under $25^{\circ} \mathrm{C}$. The samples were cut into circular with the diameter of $12.7 \mathrm{~mm}$ and thickness of $2 \mathrm{~mm}$.

The mechanical properties of the cured silicone rubber were tested by GALDABINI SUN500 tensile tester (Italy) at room temperature. The samples were cut into dumbbell shape. The extension rate was $50 \mathrm{~mm} / \mathrm{min}$. 


\section{Results and Discussion}

\section{Characterization of Modified Nano- $\mathrm{Al}_{2} \mathrm{O}_{3}$}

FT-IR spectra of modified nano- $\mathrm{Al}_{2} \mathrm{O}_{3}$ (Fig.1) were tested to confirm the effective functionalization of nano- $\mathrm{Al}_{2} \mathrm{O}_{3}$ with $\mathrm{KH} 550$. It is shown that the stretching and bending vibration absorption peaks at $3436 \mathrm{~cm}^{-1}$ and $1630 \mathrm{~cm}^{-1}$ represent $-\mathrm{OH}$ and $\mathrm{H}-\mathrm{OH}$, indicating the existence of hydroxyl on the nano- $\mathrm{Al}_{2} \mathrm{O}_{3}$ surface. After the modification with $\mathrm{KH} 550$, the absorption position and peak intensity of nano- $\mathrm{Al}_{2} \mathrm{O}_{3}$ particles changes obviously. The absorption peak at $1566 \mathrm{~cm}^{-1}$ represents $\mathrm{N}-\mathrm{H}$ bending, the absorption peak at $2930 \mathrm{~cm}^{-1}$ represents the stretching vibration of $-\mathrm{CH}_{2}, 1440 \mathrm{~cm}^{-1}$ and $1340 \mathrm{~cm}^{-1}$ represent the deformation vibration of $-\mathrm{CH}_{2}$ and $-\mathrm{CH}_{3}$, and 1018 $\mathrm{cm}^{-1}$ represents the $\mathrm{Si}-\mathrm{O}-\mathrm{Si}$ bond, which indicate that $\mathrm{KH} 550$ has been grafted onto the surface of $\mathrm{Al}_{2} \mathrm{O}_{3}$ nanoparticles.

Thermal gravimetric analysis (TGA) was allowed to quantitative analyze the grafting density of the KH550 units on the surface of nano- $\mathrm{Al}_{2} \mathrm{O}_{3}$ accurately. The weight loss of nano- $\mathrm{Al}_{2} \mathrm{O}_{3}$ and $\mathrm{KH} 550$ modified nano- $\mathrm{Al}_{2} \mathrm{O}_{3}$ in the range of 40 to $800^{\circ} \mathrm{C}$ is shown in Fig. 2. The thermal stability of $\gamma-\mathrm{Al}_{2} \mathrm{O}_{3}$ is relatively stable and no decomposition under $800^{\circ} \mathrm{C}$. The weight loss in the temperature range of 40 to $800^{\circ} \mathrm{C}$ is only $12.32 \%$, mainly the removal of surface adsorbed water. However, the thermal stability of modified nano- $\mathrm{Al}_{2} \mathrm{O}_{3}$ is worse than the unmodified nano- $\mathrm{Al}_{2} \mathrm{O}_{3}$, mainly contributed to the thermal decomposition of $\mathrm{KH} 550$ on the surface of nano- $\mathrm{Al}_{2} \mathrm{O}_{3}$. Thus the amount of grafted $\mathrm{KH} 550$ on nano- $\mathrm{Al}_{2} \mathrm{O}_{3}$ can be calculated from the TGA data by measuring the difference of weight loss, is about $26.14 \%$.

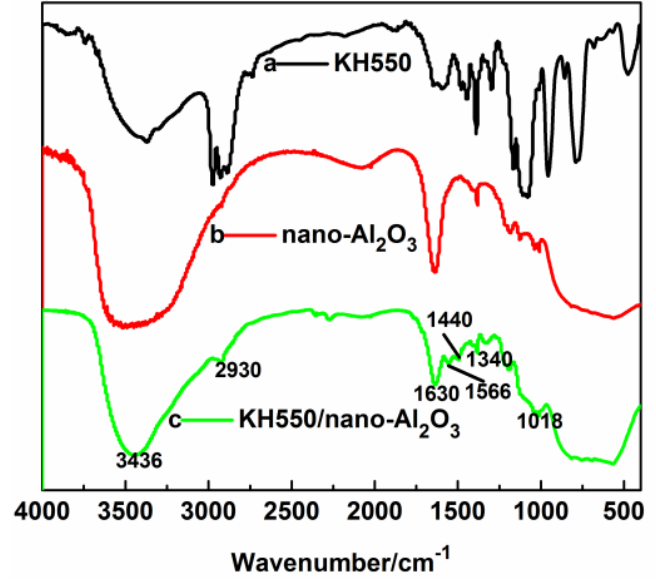

Fig.1 FT-IR of KH550, nano- $\mathrm{Al}_{2} \mathrm{O}_{3}$ and $\mathrm{KH} 550 /$ nano- $\mathrm{Al}_{2} \mathrm{O}_{3}$

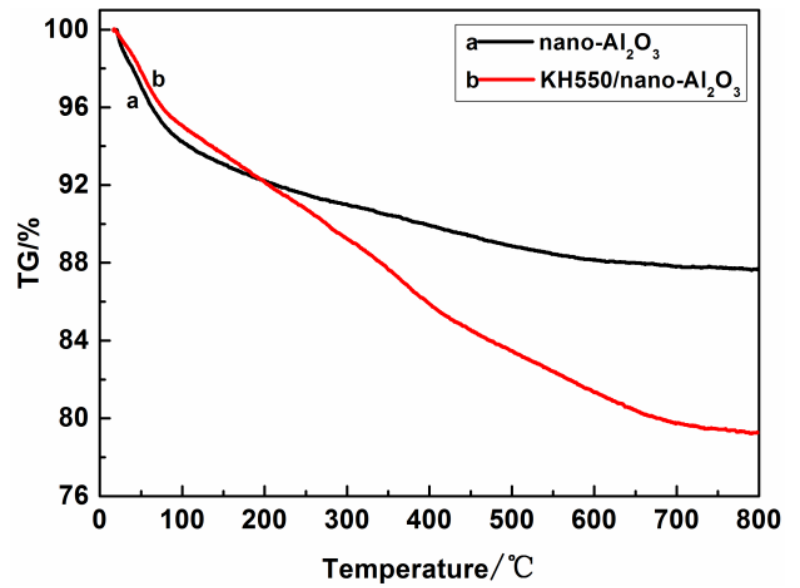

Fig.2 TGA curves of nano- $\mathrm{Al}_{2} \mathrm{O}_{3}$ and $\mathrm{KH} 550 /$ nano- $\mathrm{Al}_{2} \mathrm{O}_{3}$

\section{Optical Property}

Nano- $\mathrm{Al}_{2} \mathrm{O}_{3}$, with remarkable dispersion, is easy mixing with dispersant, therefore it has excellent transparency. The transmittance of the phenyl silicone rubber composites is shown in Fig.3. It can be seen from Fig.3, the transmittance of phenyl silicone rubber composites drops with the increase of nano- $\mathrm{Al}_{2} \mathrm{O}_{3}$. The transmittance of pure phenyl silicone rubber is about $90 \%$ in the visible wavelength region, which indicates the optical transparency of phenyl silicone rubber is very good. The composites, with the addition of nano- $\mathrm{Al}_{2} \mathrm{O}_{3}$, displays obvious shielding effect in the ultraviolet region, especially in the UV (320-400nm) region reveals remarkable absorption effect. In addition, when the mass content of nano- $\mathrm{Al}_{2} \mathrm{O}_{3}$ is $0.3 \%$, the transmittance of phenyl silicone rubber composites has a sharp drop. This maybe that the increase amount of nano- $\mathrm{Al}_{2} \mathrm{O}_{3}$ results in nano- $\mathrm{Al}_{2} \mathrm{O}_{3}$ agglomerating in the phenyl silicone rubber. The agglomeration of nano- $\mathrm{Al}_{2} \mathrm{O}_{3}$ can effectively shield and absorb ultraviolet light, but also result in the transmittance of visible light declining inevitably. 


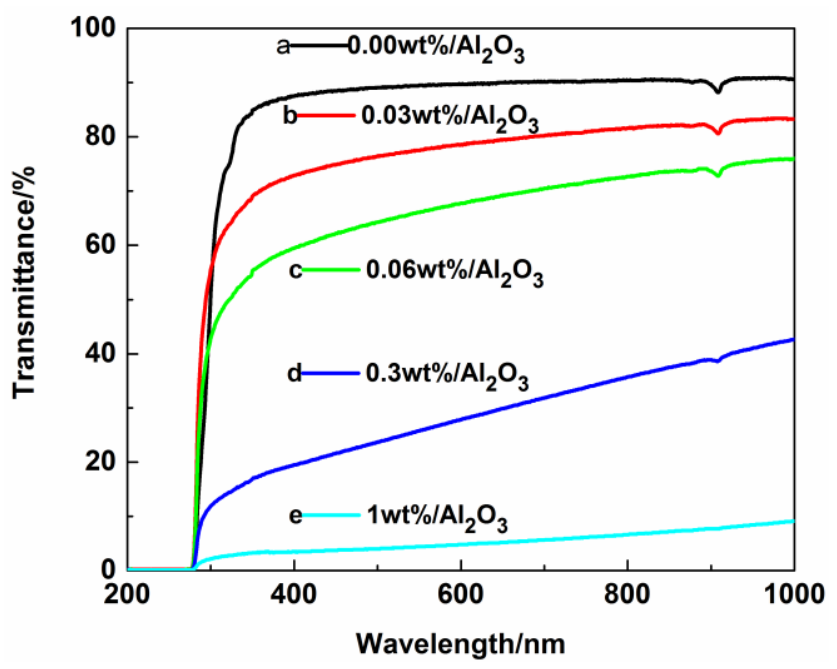

Fig.3 The transmittance of composites with various nano- $\mathrm{Al}_{2} \mathrm{O}_{3}$ contents

\section{Thermal Property}

$\gamma-\mathrm{Al}_{2} \mathrm{O}_{3}$ possesses favorable thermal stability. Fig.4 displays the influence of nano- $\mathrm{Al}_{2} \mathrm{O}_{3}$ on the thermal conductivity of composites. It is observed that the thermal conductivity of various nano- $\mathrm{Al}_{2} \mathrm{O}_{3}$ filled phenyl silicone rubber with the filler loading is from $0.13 \mathrm{~W} \cdot \mathrm{m}^{-1} \cdot \mathrm{K}^{-1}$ up to 0.216 $\mathrm{W} \cdot \mathrm{m}^{-1} \cdot \mathrm{K}^{-1}$. In the dispersion system with low mass content of nano- $\mathrm{Al}_{2} \mathrm{O}_{3}$, few particles in the composite system touch each other, and the polymer matrix is also continuous. The contribution of nanoparticles on the thermal stability of the composites seems to be less than the phenyl silicone rubber matrix. While the filler mass content is more than $0.06 \%$, the thermal conductivity starts to decrease. It may be due to the agglomeration of some nano- $\mathrm{Al}_{2} \mathrm{O}_{3}$ particles in the phenyl silicone rubber. Amounts of nano- $\mathrm{Al}_{2} \mathrm{O}_{3}$ particles touch each other to hinder the formation of conductive chains, which greatly contribute to the decrease of thermal conductivity of composites.

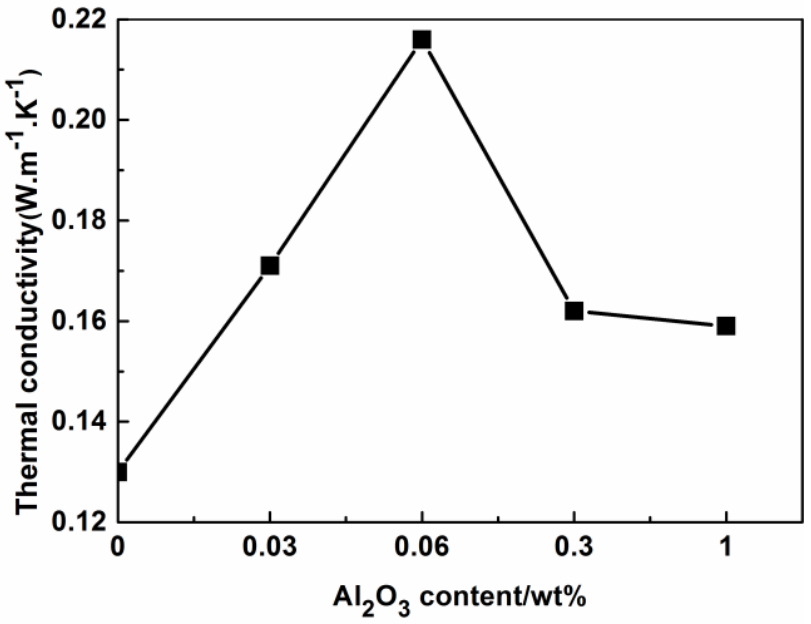

Fig.4 The effect of nano- $\mathrm{Al}_{2} \mathrm{O}_{3}$ on thermal conductivity of phenyl silicone rubber

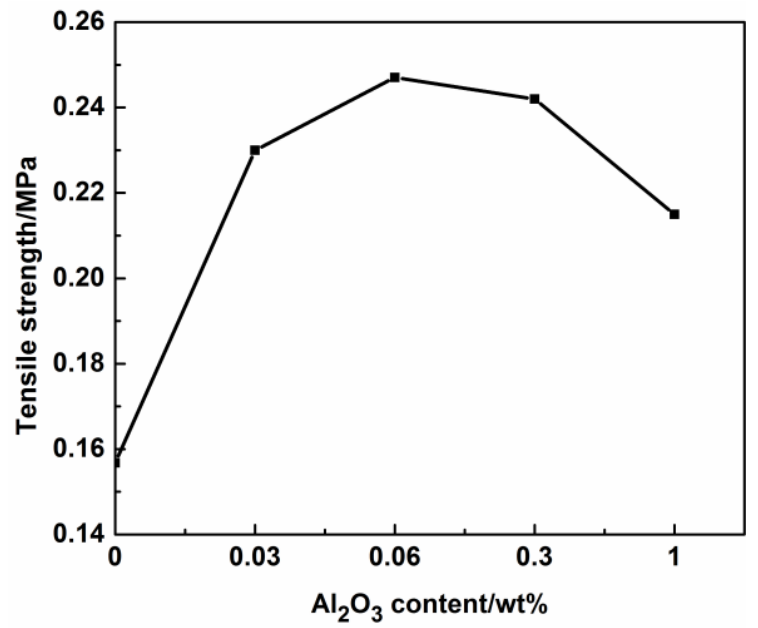

Fig.5 The tensile strength curve of composites with various nano- $\mathrm{Al}_{2} \mathrm{O}_{3}$ contents

\section{Mechanical Property}

As is well known, nanoparticles have predominant reinforcing effect to silicone rubber ${ }^{[15]}$. Nano- $\mathrm{Al}_{2} \mathrm{O}_{3}$ has natural characteristics of high strength, high hardness. The tensile strength of the phenyl silicone rubber filled with different content of nano- $\mathrm{Al}_{2} \mathrm{O}_{3}$ is shown in Fig.5. While the content of nano- $\mathrm{Al}_{2} \mathrm{O}_{3}$ is less than $1 \mathrm{wt} \%$, the tensile strength of phenyl silicone rubber composites increases little as the raise of the filler content, with the highest value less than $0.25 \mathrm{MPa}$ at the mass 
content of $0.06 \%$. A small amount of nano- $\mathrm{Al}_{2} \mathrm{O}_{3}$ added into phenyl silicone rubber will increase the crosslinking density of the phenyl silicone rubber, meanwhile increase the tensile strength. While excess nano- $\mathrm{Al}_{2} \mathrm{O}_{3}$ will weaken the interaction between the polymer chain segments. And the interface interaction between the two increase with the increase of the filler loading, so the tensile strength decreased.

\section{Conclusion}

In this paper, the effects of nano- $\mathrm{Al}_{2} \mathrm{O}_{3}$ on the properties of phenyl silicone rubber were investigated. The results revealed that the low loading fillers had a little influence on thermal and mechanical properties. When the addition of nano- $\mathrm{Al}_{2} \mathrm{O}_{3}$ is $0.06 \mathrm{wt} \%$, the composites showed higher thermal conductivity of $0.216 \mathrm{~W} \cdot \mathrm{m}^{-1} \cdot \mathrm{K}^{-1}$ and higher tensile strength of $0.25 \mathrm{MPa}$, comparing to the pure phenyl silicone rubber. However, a change of nano- $\mathrm{Al}_{2} \mathrm{O}_{3}$ concentration had great effect on the transmittance of the phenyl silicone rubber. The mass content of nano- $\mathrm{Al}_{2} \mathrm{O}_{3}$ is $0.3 \%$, the transmittance of composites had dropped to $42.7 \%$ in the visible region, nearly half of the pure phenyl silicone rubber, which indicates that nano- $\mathrm{Al}_{2} \mathrm{O}_{3}$ has a high light absorption to phenyl silicone rubber.

\section{References}

[1] B.X. Du, Z.L. Ma, Y. Gao, T. Han, Effect of Ambient Temperature on Electrical Treeing Characteristics in Silicone Rubber, IEEE Transactions on Dielectrics and Electrical Insulation. 18 (2011), 401-407.

[2] L. Yang, Preparation, Characterization of Fire Retardant Methyl Vinyl Silicone Rubber Based Cable Covering Materials, Procedia Engineering. 43 (2012), 552-555.

[3] X. Wang, W. Dou, Preparation of graphite oxide (GO) and the thermal stability of silicone rubber/GO nanocomposites, Thermochimica Acta. 529 (2012), 25-28.

[4] L.C. Sim, S.R. Ramanan, H. Ismail, K.N. Seetharamu, T.J. Goh, Thermal characterization of $\mathrm{Al}_{2} \mathrm{O}_{3}$ and $\mathrm{ZnO}$ reinforced silicone rubber as thermal pads for heat dissipation purposes, Thermochimica Acta. 430 (2005), 155-165.

[5] J.W. Zha, Z.M. Dang, W.K. Li, Y.H. Zhu, G. Chen, Effect of Micro- $\mathrm{Si}_{3} \mathrm{~N}_{4}$-nano- $\mathrm{Al}_{2} \mathrm{O}_{3} \mathrm{Co}$-filled Particles on Thermal Conductivity, Dielectric and Mechanical Properties of Silicone Rubber Composites, IEEE Transactions on Dielectrics and Electrical Insulation. 21 (2014), 1989-1996.

[6] M. Digne, P. Sautet, P. Raybaud, H. Toulhoat, E. Artacho, Structure and stability of aluminum hydroxides: A theoretical study, Journal Of Physical Chemistry B. 106 (2002), 5155-5162.

[7] H.J. Song, Z.Z. Zhang, X.H. Men, Effect of nano- $\mathrm{Al}_{2} \mathrm{O}_{3}$ surface treatment on the tribological performance of phenolic composite coating, Surface \& Coatings Technology. 201 (2006), 3767-3774.

[8] K.G. Chandrappa, T.V. Venkatesha, Generation of gamma- $\mathrm{Al}_{2} \mathrm{O}_{3}$ Microparticles by Hybrid Electrochemical-Thermal Method and its $\mathrm{Zn}$-gamma- $\mathrm{Al}_{2} \mathrm{O}_{3}$ Composite Coating for Corrosion Protection, Journal of the American Ceramic Society. 95 (2012), 2298-2306.

[9] C. Ma, Y. Chang, W. Ye, W. Shang, C. Wang, Supercritical preparation of hexagonal gamma-alumina nanosheets and its electrocatalytic properties, Journal Of Colloid And Interface Science. 317 (2008), 148-154.

[10]S.L. Ran, L. Gao, Electrical properties and microstructural evolution of $\mathrm{ZrO}_{2}-\mathrm{Al}_{2} \mathrm{O}_{3}-\mathrm{TiN}$ nanocomposites prepared by spark plasma sintering, Ceramics International. 38 (2012), 4923-4928. 
[11]C. Ang, Z. Yu, R.Y. Guo, A.S. Bhalla, Calculation of dielectric constant and loss of two-phase composites, Journal of Applied Physics. 93 (2003), 3475-3480.

[12] W.Y. Zhou, S.H. Qi, C.C. Tu, H.Z. Zhao, C.F. Wang, J.L. Kou, Effect of the particle size of $\mathrm{A} 12 \mathrm{O} 3$ on the properties of filled heat-conductive silicone rubber, Journal of Applied Polymer Science. 104 (2007), 1312-1318.

[13]J.W. Zha, Y.H. Zhu, W.K. Li, J.B. Bai, Z.M. Dang, Low dielectric permittivity and high thermal conductivity silicone rubber composites with micro-nano-sized particles, Applied Physics Letters. 101 (2012).

[14]L.K. Namitha, J. Chameswary, S. Ananthakumar, M.T. Sebastian, Effect of micro- and nano-fillers on the properties of silicone rubber-alumina flexible microwave substrate, Ceramics International. 39 (2013), 7077-7087.

[15]M.L. Chan, K.T. Lau, T.T. Wong, M.P. Ho, D. Hui, Mechanism of reinforcement in a nanoclay/polymer composite, Composites Part B-Engineering. 42 (2011), 1708-1712. 